\title{
Management of Ocular Setaria in Horses: A Review of 16 Cases
}

\author{
V.S. Dabas ${ }^{1}$, S.K. Tyagi ${ }^{2 *}$, S.K. Jhala ${ }^{1}$, D.N. Suthar ${ }^{1}$ and R.H. Bhatt ${ }^{3}$ \\ ${ }^{1}$ Department of Veterinary Surgery E Radiology, C.V.S.C, NAU-Navsari, Gujarat, INDIA \\ ${ }^{2}$ Department of Veterinary Surgery \& Radiology, COVAS, SVPUAT-Meerut, INDIA \\ ${ }^{3}$ Teaching Veterinary Clinical Complex, C.V.S.C, JAU-Junagarh, Gujarat, INDIA \\ *Corresponding author: SK Tyagi; E-mail: surbhiivri@gmail.com
}

Received: 16 Jan., 2020

Revised: 30 Jan., 2021

Accepted: 02 Feb., 2021

\begin{abstract}
Sixteen cases of horse presented with the worm in the anterior chamber of eyes were managed surgically in xylazine sedated standing horses using either blade incision $(\mathrm{n}=14)$ or needle paracentesis $(\mathrm{n}=2)$, near limbus. Vision was completely restored in all the cases with complete resolution of symptoms like corneal opacity, corneal oedema and epiphora within 25-30 days, post operatively.
\end{abstract}

\section{HIGHLIGHTS}

(0 Sixteen horse of either sex presented to the clinic with the chief complaints like worm in the eye, whiteness in the eye or epiphora were taken as the subject of the study.

(0) The cases were successfully managed with surgical removal of the eye worm from the anterior chamber followed by complete restoration of the vision of the affected horses.

Keywords: Anterior chamber, Equine, Eye worm, Intraocular setariosis, Needle puncture

One of the most common eye affections in horse is the presence of eye worm, which can be both intraocular and extraocular. Extraocular nematodiasis is caused by thelezia species, whereas, intraocular setariosis is caused by larval stages of nematode setaria. In earlier presented cases lacrimation and conjunctival hyperaemia is seen, this is followed by the cloudiness of the cornea and ultimately the corneal opacity, photophobia may also be seen in some cases. Similar of lesions and symptoms are also observed in Thelezia infection of the eye but in that case the worms are found in conjunctival sac only.

Seteria worm, commonly inhabits the peritoneal cavity of ruminants and the immature stages of worm may invade the central nervous system and can move in the anterior chamber of eyeball leading to ocular setariosis (Yadav et al., 2006). The condition can be unilateral or rarely bilateral. There are many reports about the intraocular setariosis in equines from all over the India (Tamil Mahan et al., 2013; Malik and Amarpal, 2016; Patel et al., 2016;
Simon et al., 2017). The present article describes the management of intraocular setariosis in 16 horses and their successful surgical removal.

\section{MATERIALS AND METHODS}

Sixteen horses of either sex and different age groups coming to the clinics with the presence of eye worm in the anterior chamber were taken as the subject of the study. Animals were presented with the history of corneal opacity, corneal oedema, epiphora and presence of worm inside the eye (Fig. 1). A thorough examination of anterior chamber was done using direct and lateral illumination.

How to cite this article: Dabas, V.S., Tyagi, S.K., Jhala, S.K., Suthar, D.N and Bhatt, R.H. (2021). Management of Ocular Setaria in horses: A review of 16 cases. J. Anim. Res., 11(1): 143-146.

Source of Support: None; Conflict of Interest: None क क 


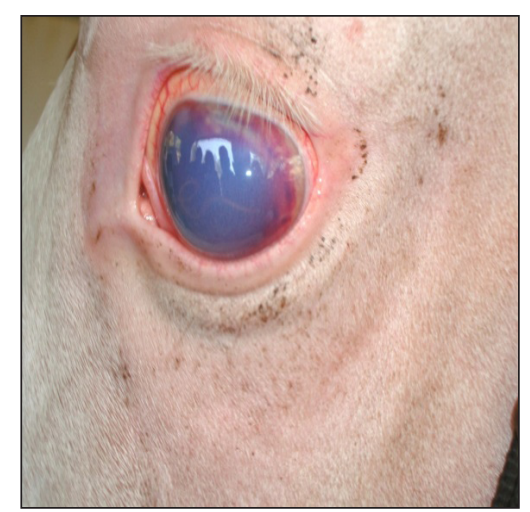

Fig. 1: Worm in the eye before surgery

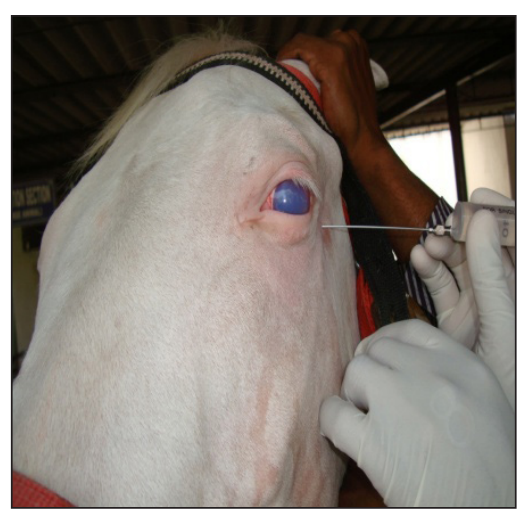

Fig. 2: Retrobulbar nerve block in a horse

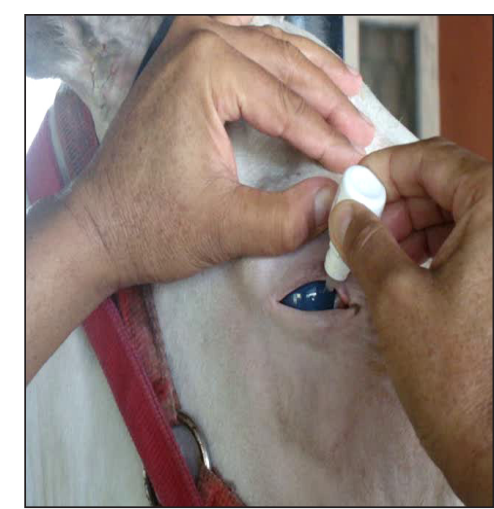

Fig. 3: Instillation of proparacain for corneal desensitization

\section{Restraining and anaesthesia}

The procedure was performed in Xylazine sedated standing horse along with supraorbital, auriculopalpebral and retrobulbar nerve blocks (Fig. 2). Corneal desensitization was achieved by using topical proparacaine (Fig. 3).

\section{Surgical procedure}

After trimming of eye lashes of affected side, eye lids were retracted. Removal of worm was done by a clear corneal stab incision with BP blade No. 11 between 3 to 9 'O'clock position in 14 cases (Fig. 4). In other two cases, a 16 gauge needle was used to puncture the limbus and expel the worm (Fig. 5). In both the techniques, the worm was flushed out along with the outflow of the aqueous humour and the incision was left as such. In one case the worm was not expelled out which was then removed by using capsular forceps (Fig. 6). Mefloxacin and flubiprofen eye drops were prescribed for instillation in the affected eye. Whereas; in cases of corneal oedema $6 \%$ sodium chloride was administered topically. Collected worms were washed and observed microscopically (Fig. $7 \& 8$ ).

\section{RESULTS AND DISCUSSION}

Of the 16 horses affected, 10 were male and 6 were females. The percentage of male and female affected depends on the population of particular animal in particular area. In north India, the female population is more as they are used for social activities like marriages, whereas in western India, male horses are kept for sports purpose. Breedwise Marwari $(n=5)$, Sindhi $(n=4)$, Kathi $(n=3)$, Sindhi $x$
Marwadi ( $n=2)$ and non-descript $(n=2)$ breeds were recorded. All the cases presented were having unilateral affection with right side ( $\mathrm{n}=9)$ affected comparatively more than left one $(n=7)$. Though, involvement of the one eye is commonly observed but bilateral occurrence is also reported (Shin et al., 2002; Buchoo et al., 2005). Only one worm was observed in all the cases except for one horse; wherein two worms were retrieved from the anterior chamber of the same eye.

Mritunjay et al. 2011 have reported a higher prevalence of ocular setariosis in animals in summer and autumn seasons when the vectors (Anopheles peditaneniatus and Culexnil giricus) are most prevalent. A seasonal predisposition was also observed in the present study, wherein all cases were recorded from October to April and no cases were recorded in summer season.

The cases were presented within one week to three weeks of appearance of symptoms, except for two, which were presented one month after the onset of the symptoms. In these two cases the corneal opacity was extensive and it was very difficult to visualize the nematode, in addition, the fluid in the anterior chamber had also became viscous and the movement of the worms was also very sluggish. In one of these cases, the worm was not retrieved even after stab incision and the anterior chamber also collapsed. Later, the worm was removed using castrovejo's eye forceps and the anterior chamber was reformed again by inflating air inside. Thus early presented cases have a better prognosis in terms of visualization of worm in addition to lesser trauma to the cornea by the worm and the surgical treatment should be performed as soon as possible to prevent complications. 


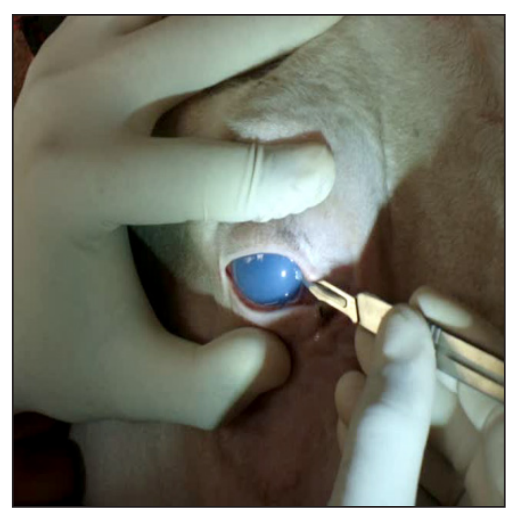

Fig. 4: Nick incision with B.P. blade for Fig. 5: Needle stab for eye worm retrieval eye worm retrieval

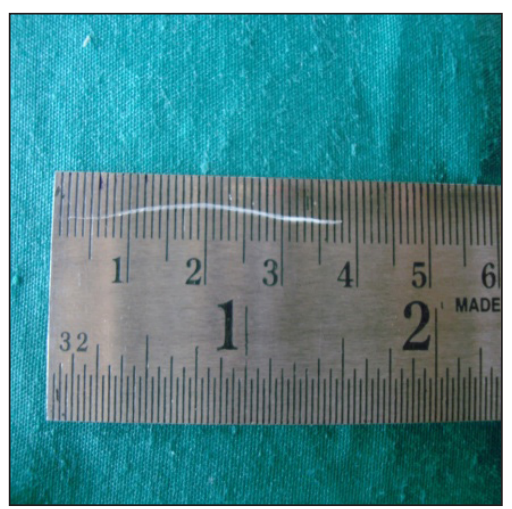

Fig. 7: Gross Photograph of the parasite removed from the eye
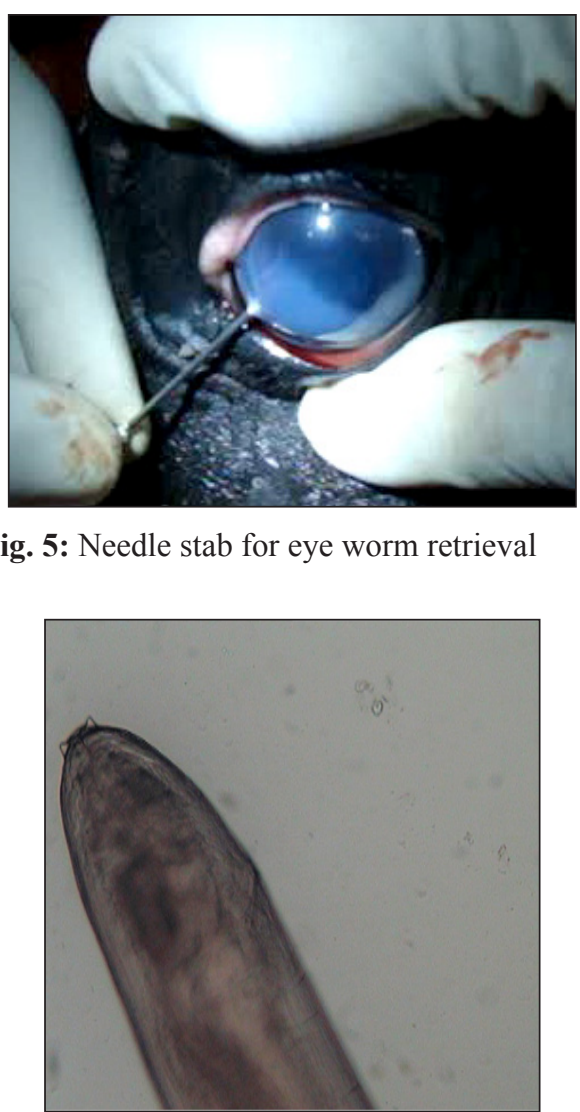

Fig. 8: Microscopic photographs papilla at anterior end of the parasite

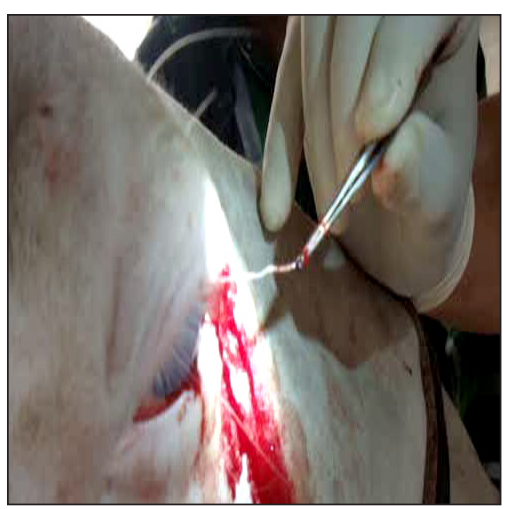

Fig. 6: Removal of lodged eye worm using forceps

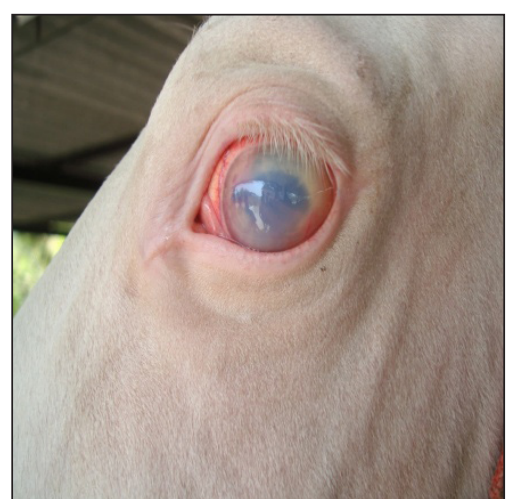

howing Fig. 9: 2-3 week follow-up photographs showing reduction in corneal opacity
A clear corneal stab incision was made with the help of B.P. blade number 11 in all the cases except for two where needle puncture was made using 16 number needle. Gopinathan et al. 2012 have also used these two techniques for removal of eye worm viz., stab incision by blade or puncture by $16 \mathrm{G}$ needle.

No complication like eye ball shrinkage due to aqueous effusion was observed in the present study. In some cases the worm gets lodged at the site of incision and can be recovered using capsular forceps.

For the puncture with nick incision, 10-2 o' clock or 3-9 o' clock positions can be used and generally the corneal wound is left unstitched. Incision at 10-2 o' clock position has been proposed by many workers (Jamelka, 1976; Kalpravidh et al., 1992; Patil et al., 2012) and it requires the animal to be recumbent requiring sedation or general anaesthesia. However, incision at 3-9 o' clock position has also been used (Gopinathan et al., 2012).
There are reports on the successful removal of intraocular parasites by aspiration using a 16-gauge needle connected to a 5-mL syringe (Gangwar et al., 2008; Yang et al., 2014). In an earlier report, an 18-gauge needle was used but the worm could not be removed and additional incision on the cornea was required (Tuntivanich et al., 2011). However, in the present study, 16 gauge needle was used to puncture the anterior chamber near limbus and worm was removed, without aspiration and no additional incision was required to remove the worm.

The operated eyes developed a localized corneal oedema/ opacity at the site of corneal stab (Fig. 9), which resolved gradually. A combination of antibiotics and corticosteroids along with $6 \%$ sodium chloride was administered postoperatively to reduce intraocular inflammation and corneal edema/opacity. Similar findings of focal corneal opacity at the site of stab incision have also been reported in earlier studies (Sharma et al., 2005; Patil et al., 2012). All eyes showed uneventful recovery in terms of lacrimation, 
blepherospasm and restoration of corneal transparency within 20 to 30 days, as also reported by Buchoo et al. (2005) and Jaiswal et al. (2006).

\section{CONCLUSION}

To conclude, equine ocular setariosis can successfully be managed surgically in xylazine sedated standing horses under retrobulbar nerve block through corneal puncture using stab incision by blade or needle puncture, near limbus anywhere between 3-9 o'clock position, depending upon the movement of the worm.

\section{REFERENCES}

Buchoo, B.A., Pandit, B.A., Shahardar, R.A., Parrah, J.D. and Darzi, M. 2005. Surgical management and prevalence of ocular filariosis in equines. Indian Vet. J., 82: 81-82.

Gangwar, A.K., Sangeetha, D., Singh, H.N. and Singh, A. 2008. Ocular filariasis in equines. Indian Vet. J., 85: 547-548.

Gopinathan, A., Singh, K., Saxena, A.C., Khurana, K.L. and Amarpal. 2013. Evaluation of two techniques for management of ocular setariasis in horses. Res. Opin. Anim. Vet. Sci., 3: 407-411.

Jamelka, E.D. 1976. Removal of Setaria digitata from the anterior chamber of the equine eye. Vet. Med. Small Anim. Clinician., 71: 673-675.

Kalpravidh, M., Bramasa, A. and Kalpravidth, C. 1992. Surgical removal of intraocular parasites from the anterior chambers of the horse eyes. Thailand J. Vet. Med., 22: 13-20.

Malik, A.R. and Amarpal. 2016. Equine ocular setariasis and its management. J. Exp. Biol. Agric. Sci., 4: 139-143.
Mritunjay, K., Monsang, S.W., Pawde, A.M., Singh. S.K., Madhu, D.N., and Zama, M.M.S. 2011. Post-surgical healing effect of placentrex in equine (Equus cabalus) ocular setariasis: A review of 22 cases. Indian J. Field Vets., 6: 7173.

Patil, D., Kelawala, D., Parikh, P., Sheth, M., Sini, K. and Parmar, J. 2016. Surgical management of ocular setariasis in horses. Indian J. Vet. Surg., 37: 44-47.

Patil, D.B., Parikh, P.V., Joy, N., Jhala, S.K., Dar, M.U.D. and Tiwari, D.K. 2012. Equine eye worm: a review of 50 cases. Indian J. Vet. Surg., 33: 61-62.

Shin, S., Cho, K. and Wee, S. 2002. Ocular infection of cattle with Setaria digitata. J. Vet. Med. Sci., 64: 7-10.

Simon, M. S., Ramprabhu, R., Jeyathilakan, S. and Pazhanivel., N. 2017. Surgical management of worm in the eye of a pony - A Case Report. Indian Vet. J., 94: 50-52.

Tamilmahan, P., Zama, M., Pathak, R., Muneeswaran, N. and Karthik, K. 2013. A retrospective study of ocular occurrence in domestic animals: 799 cases. Vet World., 6: 274-276.

Tuntivanich, N., Sonthaya, T. and Pranee, T. 2011. Success of anterior chamber paracentesis as a treatment for ocular setariasis in equine eye: case report. J. Equine Vet. Sci., 31: 8-12.

Yadav, A., Kumar, A., Bhadwal, M.S., Khajuria, J.K. and Gupta, A. 2006. Ocular setariosis in horses: A case study. J. Vet. Parasitol., 20: 183-184.

Yang, J.Y., Cho, Y.J., Choi, S.K and Cho, G.J. 2014. Modified needle aspiration technique for extracting live eye worm in a thoroughbred horse. J. Anim. Vet. Adv., 13: 998-1001. 